\title{
Article \\ Effect of Grain Refinement on the Dynamic, Mechanical Properties, and Corrosion Behaviour of Al-Mg Alloy
}

\author{
Haitham M. Ahmed ${ }^{1}$ (D), Hussin A. M. Ahmed ${ }^{1}$ (D), Mohammed Hefni ${ }^{1}$ (D) and Essam B. Moustafa $^{2, *(D)}$ \\ 1 Department of Mining Engineering, King Abdulaziz University, Jeddah 21589, Saudi Arabia; \\ hmahmed@kau.edu.sa (H.M.A.); haahmed@kau.edu.sa (H.A.M.A.); mhefni@kau.edu.sa (M.H.) \\ 2 Department of Mechanical Engineering, King Abdulaziz University, Jeddah 22254, Saudi Arabia \\ * Correspondence: abmostafa@kau.edu.sa
}

check for updates

Citation: Ahmed, H.M.; Ahmed, H.A.M.; Hefni, M.; Moustafa, E.B. Effect of Grain Refinement on the Dynamic, Mechanical Properties, and Corrosion Behaviour of Al-Mg Alloy. Metals 2021, 11, 1825. https:// doi.org/10.3390/met11111825

Academic Editor: Frank Czerwinski

Received: 25 October 2021

Accepted: 9 November 2021

Published: 13 November 2021

Publisher's Note: MDPI stays neutral with regard to jurisdictional claims in published maps and institutional affiliations.

Copyright: (c) 2021 by the authors. Licensee MDPI, Basel, Switzerland. This article is an open access article distributed under the terms and conditions of the Creative Commons Attribution (CC BY) license (https:/ / creativecommons.org/licenses/by/ $4.0 /)$.

\begin{abstract}
In this investigation, aluminium Al-2.5\% Mg cast alloy was modified by adding $0.5 \mathrm{Ti}$ and $0.1 \mathrm{~B}$ wt \% modifiers to investigate their impact on the dynamic behaviour, as well as the mechanical and microstructure properties. The dynamic properties were analysed experimentally using a free vibration impact test and predicted using finite element methods. This study used a high-resolution polarised optical microscope to analyse the microstructure of the studied alloys and X-ray Powder Diffraction (XRD) analysis to determine the developed phases. Microstructure and mechanical properties were mostly enhanced as a result of grain refining during solidification and through the metal segregation process. The microstructure analysis of the modified alloy showed a significant improvement in the grain refinement; hence, the grains were 10 times finer than the cast alloy. The modified Al-2.5\% Mg/Ti-B alloy demonstrated reduced inter-granular corrosion (IGC) than the $\mathrm{Al}-2.5 \% \mathrm{Mg}$ standard cast alloy. By incorporating Ti-B modifiers into the composition of the cast Al-Mg alloy, the ultimate tensile strength (UTS), strain $(\varepsilon)$, and hardness values (HV) were increased by $30.5 \%, 100 \%$, and $18.18 \%$, respectively. The dynamic properties of the modified alloy showed an enhancement in the resonant $\left(f_{n}\right)$ and damping ratio $(\zeta)$ by $7 \%$ and $68 \%$, respectively. The predicted resonance frequencies of the investigated alloys showed results close to the experimental dynamic tests.
\end{abstract}

Keywords: Al-Mg alloy; Ti-B modifiers; dynamic; mechanical; corrosion; hardness; damping

\section{Introduction}

Due to their low weight and high deformability, aluminium alloys are the foundation of the automotive and aerospace industries. These alloys are frequently utilised in the food industry, as well as in automotive and chemical equipment. Moreover, they have high specific strengths and good mechanical properties; thus, they are preferred for ordinary sheet metal and marine applications. The improvement of aluminium alloys may be accomplished by improving their mechanical characteristics; as a result, the use of reinforcing particles and additives becomes increasingly necessary to enhance the performance of aluminium alloys and their composites [1-4]. Modifying Ti, B, and $\mathrm{B}_{4} \mathrm{C}$ has significantly affected the microstructure of grain refinement [5]. These modifiers play an essential role in reducing grain size and displaying the dendritic structure during manufacturing. Furthermore, they enhance the mechanical properties of the material. However, these dynamic properties have not been investigated in the literature.

As a result, various particles and alloying elements, including $\mathrm{Al}_{2} \mathrm{O}_{3}, \mathrm{SiC}$, and $\mathrm{TiB}_{2}$, are employed to refine and fine-tune aluminium alloy grains and surface morphology to improve the mechanical characteristics [6,7]. Grain refining can be accomplished using rapid solidification and repeated deformations, dissolving the modifiers using molten metal, lasers, and friction stir processing [8,9]. The first technique depends on the molten metal's melting point and elemental structure and the amount of molten metal present $[10,11]$. The phase of the matrix may also influence the structure of the refined grain [12]. Furthermore, 
modifying elements such as titanium and boron have been used as grain refiners in various aluminium alloy series $[13,14]$. Many researchers have focused on the impact of these components on grain refinement and particle size on mechanical characteristics [15-17]. The modifiers enhanced the cast alloy in two ways through grain refinement and decreased porosity during the casting process [18]. Aluminium is an excellent material for manufacturing energy-absorbing structures. The value of the parameters describing the mass-specific energy absorption capacity for aluminium is double that of mild steel and equivalent to steel alloys [19]. The mechanical characteristics of 6082-T6 and 7075-T6 aluminium alloys have been utilised for finite element method (FEM) modelling applications, particularly when dynamic experiments are performed, such as car crashes, explosions, or ballistic strikes [20]. The relationships between erosion and corrosion are complicated, where both processes can either increase material loss or reduce overall wear [21,22]. Even though aluminium has excellent corrosion resistance, the external medium or certain alkalis can dissolve the oxide coating on the metal surfaces, resulting in corrosive metal when this film is damaged. Thus, a significant study was conducted to investigate the impact of corrosion on aluminium alloys [23].

The methods used to identify the dynamic properties of the metals and the role of reinforcement elements to enhance the structural properties were investigated in many works of literature [24,25]. The most simple and accurate method is the free vibration test, which depends on the excitation of the structure to obtain the dynamic properties. As a result of refining the grains, there are many pores and defects in the casting that can be reduced. The internal friction of the materials has long been studied to find suitable damping materials that address or account for environmental and safety concerns. The recent societal focus has been paid to various materials' damping characteristics given new factors for consideration, such as more delicate equipment, eco-friendly machines, and electronic industry needs [26]. The measurement of internal friction behaviour in terms of heat treatment and alloy composition has been used in investigating the relationship between general damping behaviour and internal microstructure, providing a better understanding of the damping mechanism process [27].

Moreover, the grain refiner's presence results in a redistribution of porosity $[28,29]$. The refined grains significantly affect the dynamic properties of alloys and their composites regarding the impedance of the refined grains of the transmitted excitation source. Fewer investigations have discussed the impact of alloying elements on the dynamic properties [30-32]; hence, the effect of refined grains in addition to $\mathrm{Al}_{2} \mathrm{O}_{3}$ nanoparticles using friction stir processing showed a significant improvement in the dynamic behaviour [33].

From the previous literature, the researchers' interest in looking for the best quantities of titanium and boron elements developed to refine aluminium grains. It was also clear that only mechanical and apparent properties would explain this improvement without experiencing the effect of such modification on dynamic properties. Therefore, the current work focuses on the effect of grain refinement on the dynamic and mechanical properties by dissolving the Ti-B modifiers into an Al-2.5\% Mg cast aluminium alloy. Hence, the primary goal is to find a new relationship between the grain refinement of the modified alloy and its dynamic properties. Furthermore, we investigate the refine action on the corrosion resistance. The FEM, implemented using the ANSYS software, was used to simulate and predict the behaviour of the resonant frequencies that represent the theoretical eigenvalues.

\section{Materials and Experiments}

\subsection{Microstructure and Mechanical Properties Test}

The investigated alloys, with chemical compositions listed in Table 1, were melted in a graphite-fireclay crucible (Aug. Gundlach KG, Grossalmerode, Germany) at a temperature of $825{ }^{\circ} \mathrm{C}$ using a $5.5 \mathrm{~kW}$ Nabertherm resistance furnace(Nabertherm $\mathrm{GmbH}$, Nuremberg, Germany). The melted composition was stirred to homogenise the alloying elements with the base melt alloy, and then, the melted cast was poured into a graphite die. After the casting process, the ingot was annealed at a temperature of $200{ }^{\circ} \mathrm{C}$ for three hours 
to remove the residual stresses that occurred during the casting process. The samples were sectioned and ground via SiC papers with numbers ranging from P320 to P4000; then, it was polished in a $20 \%$ water solution of colloidal silica-based suspension. The polished surface was electrically etched at $18 \mathrm{~V}$ using a $10 \%$ electrolyte solution (saturated solution of $\mathrm{H}_{3} \mathrm{BO}_{3}$ in $\mathrm{HF}$ ) in distilled water. Optical microscopy was used to conduct the microstructural investigation (Olympus PMG Tokyo, Japan). The grain size was measured using the standard linear intercept technique. The average grain size was measured by JMICRO Vision software (JMicroVision 1.3.4, Switzerland) using the average grain intercept (AGI) method. There are three samples chosen from different sections along with the cast alloy to ensure the grains' distribution and refinement.

Table 1. Chemical composition of investigated alloys, wt \%.

\begin{tabular}{cccccccc}
\hline Alloy & $\mathbf{M g} \%$ & $\mathbf{S i} \%$ & $\mathbf{T i} \%$ & $\mathbf{B} \%$ & $\mathbf{C r} \%$ & $\mathbf{F e} \%$ & $\mathbf{A l}$ \\
\hline $\mathrm{Al}-2.5 \% \mathrm{Mg}$ & 2.5 & 0.55 & 0 & 0 & 0.2 & 0.39 & remain \\
\hline $\mathrm{Al}-2.5 \% \mathrm{Mg}+\mathrm{TiB}$ & 2.5 & 0.71 & 0.5 & 0.1 & 0.2 & 0.38 & remain \\
\hline
\end{tabular}

X-ray diffraction (XRD) was conducted with $\mathrm{Cu}-\mathrm{K} \alpha$ radiation (Bruker Corp., Billerica, MA, USA) to study the microstructure by the heating/cooling rate of $5^{\circ} \mathrm{K} / \mathrm{min}$. In addition to the EDX, elemental analysis was used to identify the participating elements, phases, and construction of the investigated alloy. After the samples were polished and prepared, they were subjected to the hardness test. A Labsys Setaram differential scanning calorimeter (DSC; Setaram Instrumentation, Caluire, France) was used to determine the liquidus and solidus temperatures with a heating rate of $5 \mathrm{~K} / \mathrm{min}$. The Vickers hardness test (Zwick/Roell, Kennesaw, GA, USA) was employed to measure the micro-hardness of the samples with a force of $30 \mathrm{~N}$ and a dwell duration of $10 \mathrm{~s}$, which was in accordance with the ASTM E-384-17 specifications. Using the ISO 11,846 Method B, the samples were submerged in an aqueous solution comprised of $30 \mathrm{~g} / \mathrm{L} \mathrm{NaCl}$ and ten millilitres per litre concentrated $\mathrm{HCl}$ for $24 \mathrm{~h}$ to determine intergranular corrosion. The samples were immersed in the solution for $24 \mathrm{~h}$ to investigate the influence of the addition of the modifiers $\mathrm{TiB}$ on the corrosion behaviour of $\mathrm{Al}-2.5 \% \mathrm{Mg}$ aluminium alloys, respectively. Then, the samples were treated with a solution comprised of $15 \% \mathrm{HNO}_{3}$ and $85 \%$ distilled water; afterwards, the samples were dried. Next, they were washed in fresh water and dried on a drying rack. Optical microscopy was used to examine the specimens. A Zwick/Roell Z250 Allround series testing machine (ZwickRoell GmbH \& Co. KG, Ulm, Germany) was used to perform the tensile tests. Three tensile samples of each alloy were tested, and the average of these three data points was used to get the reported value. The samples had a gauge length and width of $20 \mathrm{~mm}$ and $6 \mathrm{~mm}$, respectively, which were performed according to the Russian GOST 1497-84. The dimensions of the samples used in this study are shown in Figure 1. The tensile tests were performed at a constant strain rate of $4 \mathrm{~s}^{-1}$ for all samples.

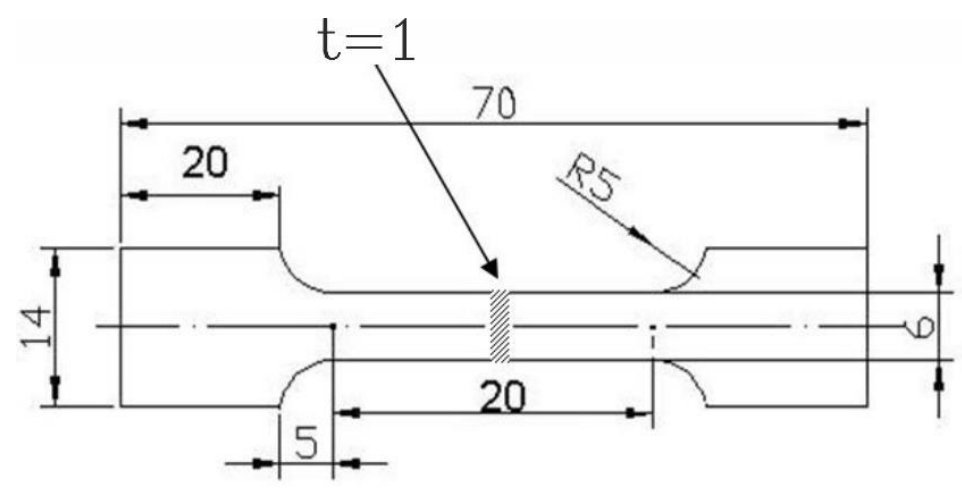

Figure 1. The tensile samples used in this paper. All dimensions are in $\mathrm{mm}$. 


\subsection{Determination of the Natural Frequency and Damping Ratio by Experiment}

The schematic diagram for the free vibration test is shown in Figure 2. A specific fixture was conducted to support the specimens acting as cantilever beams, and the piezoelectric accelerometer was used to detect the vibration response (Type 4507-B, Bruel \& Kjaer, Naeuram, Denmark). An impact hammer exciter equipped with a force transducer (Type 8206, Bruel \& Kjaer) was utilised in the excitation process. The vibration signals were gathered using the LAN-XI pulse analyser (type 3050 A-60, Bruel \& Kjaer). Pulse Lab Shop software (Bruel \& Kjaer) was used to handle the post-processing signal. The fast Fourier transform (FFT) was calculated using a 3200-line resolution and a frequency spread of $10 \mathrm{k} \mathrm{Hz}$. Ten data blocks were averaged in a linear mode. The data were averaged over ten tests in order to arrive at proper data. Once the data had been processed, it was examined using MEscope software (Vibrant Technology Inc., Scotts Valley, CA, USA). In the absence of non-destructive test scans, such as radiography or ultrasonic tests, all samples were analysed using an average of five samples for each alloy. A logarithmic decrement, Equations (1) and (2), were used to compute the damping ratio $(\zeta)$. The quality factor $(Q)$ is obtained from Equation (3) [24,34]. Figure 3 shows the principal idea in which the logarithmic decrement is calculated from the time-domain graph. Consequently, the damping ratio $(\zeta)$ measures how the materials resist the vibratory motion. The variable $x_{0}$ refers to the initial amplitude on the time-domain graph, while $x_{n}$ represents the amplitude of the oscillating wave after $n$ cycles.

$$
\begin{gathered}
\delta=\frac{1}{n} \ln \frac{x_{0}}{x_{n}} \\
\zeta=\frac{\delta}{\sqrt{4 \pi^{2}+\delta^{2}}} \\
Q=\frac{1}{2 \zeta}
\end{gathered}
$$

where

$\delta=$ Logarithmic decrement;

$n=$ Number of cycles;

$x_{0}=$ Initial amplitude at the peak;

$x_{n}=$ Amplitude of the peak after $\mathrm{n}$ cycles;

$\zeta=$ Damping ratio;

$Q=$ Quality factor.

Impact hammer

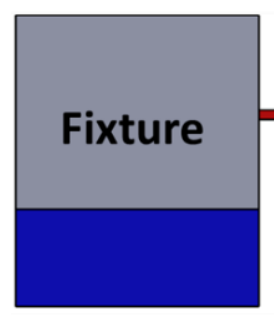

Sample

Accelerometer

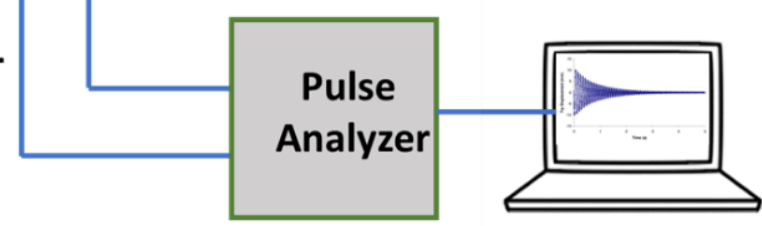

Figure 2. Schematic drawing of the free vibration impact test. 


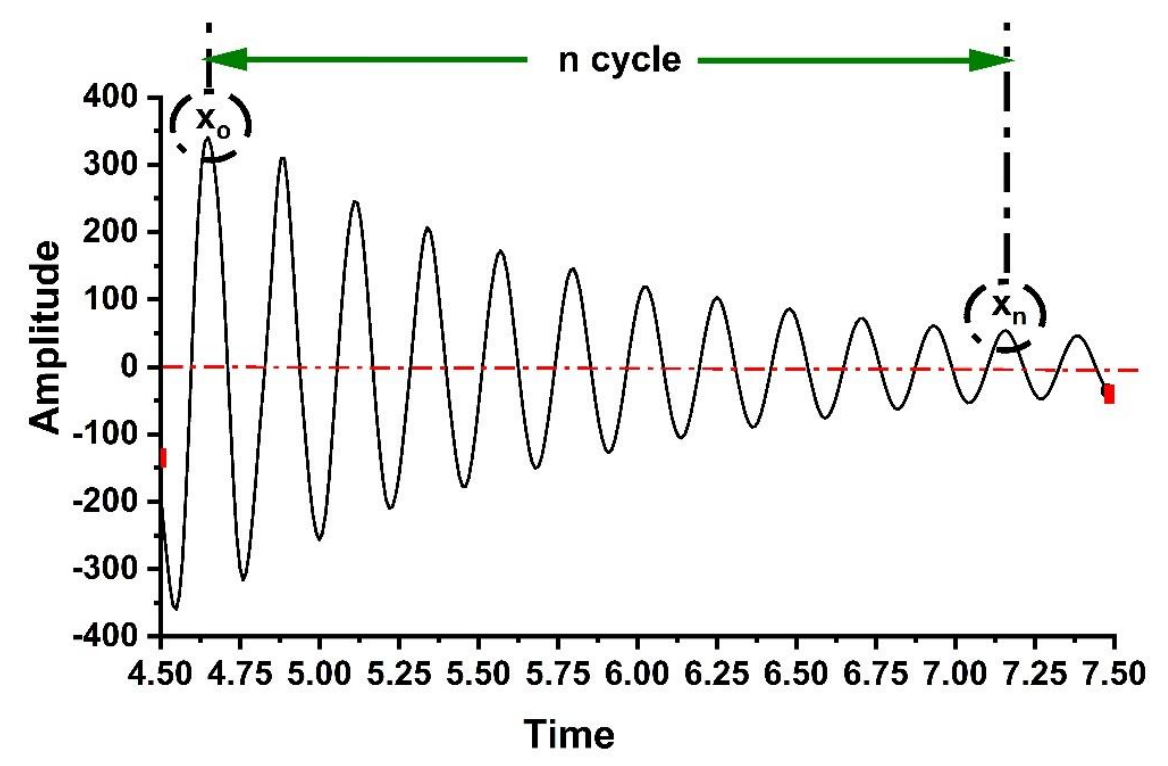

Figure 3. Time domain of the free impact test.

In order to calculate the mathematical eigenvalue of the natural frequencies, the analytical and mode shapes of the investigated material are obtained from the EulerBernoulli equation of the beam by adding boundary conditions to Equation (4); the natural frequency of the beam equation may be simplified using Equation (5):

$$
\begin{gathered}
\frac{E I d^{4} u}{\rho A d x^{4}}+\frac{d^{2} u}{\rho A d t^{2}}=0 \\
f_{n}=\frac{\alpha^{2}}{2 \pi l^{2}} \sqrt{\frac{E I}{\rho A}}
\end{gathered}
$$

where $(A)$ is the cross-section area of the modelled beam in $\mathrm{mm}^{2},(E)$ is the experimental elastic modulus obtained from the tensile test, $(I)$ is the area moment of inertia, $(l)$ is the modelled beam length, and $(\rho)$ is the density of the investigated alloy. In the first, second, and third modes, $\alpha=1.875,4.694$, and 7.854 , respectively.

\section{Results and Discussion}

\subsection{Microstructure}

Figure 4 shows the optical micrographs of the as-cast investigated alloys, Al- $2.5 \%$ $\mathrm{Mg}$, and $\mathrm{Al}-2.5 \% \mathrm{Mg} / \mathrm{TiB}$. Large grains with a dendritic structure of common alloys were observed in the as-cast $\mathrm{Al}-2.5 \% \mathrm{Mg}$ alloy. The average grain size was calculated using the average grain intercept (AGI) method.

The addition of $0.5 \% \mathrm{Ti}$ and $0.1 \% \mathrm{~B}$ during the casting process resulted in the refinement of the grains and the disappearance of the dendritic structure. The results showed that the modified alloy, $\mathrm{Al}-2.5 \% \mathrm{Mg}+\mathrm{TiB}$, had finer grain than the standard alloy by more than 10 times. The average grains size of the $\mathrm{Al}-2.5 \% \mathrm{Mg}$ and $\mathrm{Al}-2.5 \% \mathrm{Mg} / \mathrm{Ti}-\mathrm{B}$ alloys are $270 \pm 10 \mu \mathrm{m}$ and $25.7 \pm 3 \mu \mathrm{m}$, respectively. In addition, the grains of $\mathrm{Al}-2.5 \% \mathrm{Mg}+$ $\mathrm{TiB}$ alloy are equiaxed with an aspect ratio of 1.01. Figure 5 shows the SEM micrographs and the EDS point analysis of the as-cast alloys, Al-2.5\% Mg and Al-2.5\% Mg/Ti-B. It was observed that the common intermetallic phases were formed in between the dendrite arms of Al-2.5\% Mg alloy (Figure 5a,c). Two types of intermetallic particles $\left(\mathrm{Al}_{3} \mathrm{Ti}\right.$ and $\left.\mathrm{TiB}_{2}\right)$ develop and disperse in the melt and act as active sites during solidification when Al-Ti-B master alloys are added to the alloys [35]. 

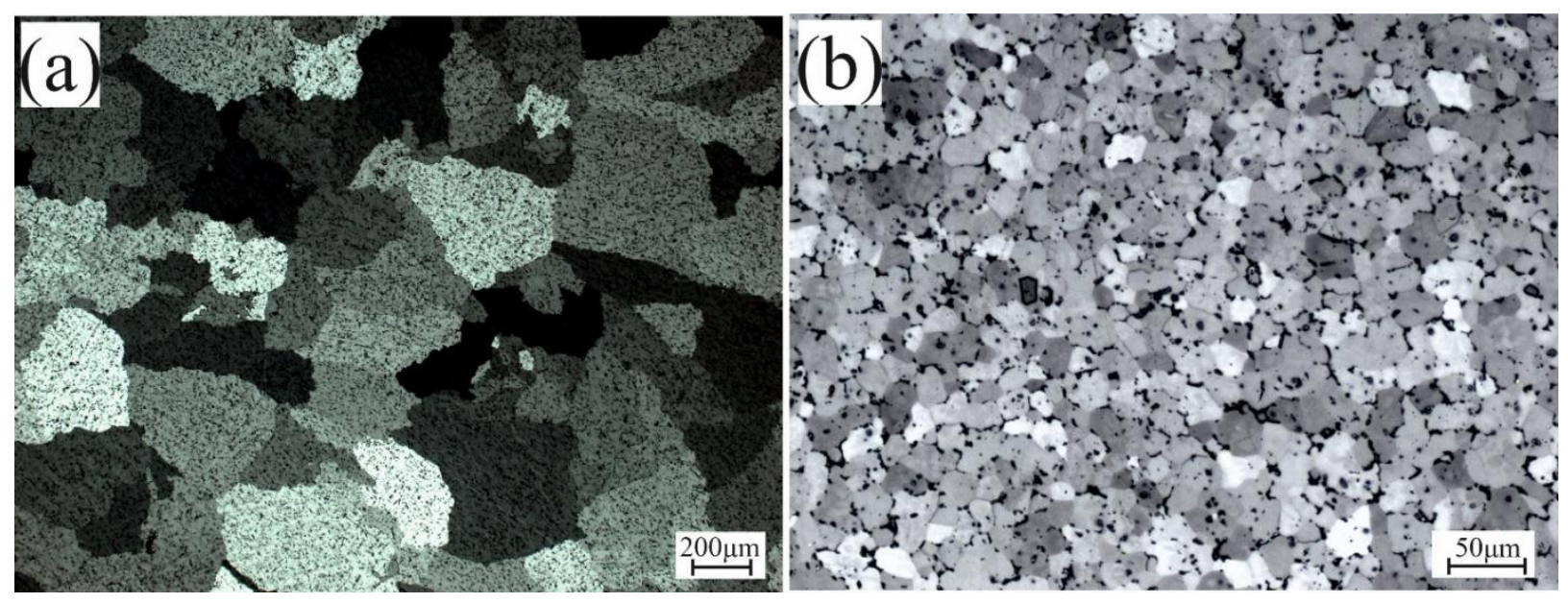

Figure 4. The as-cast optical photography of investigated alloys: (a) Al-2.5\% Mg alloy; and (b) Al-2.5\% Mg + TiB modified alloy.

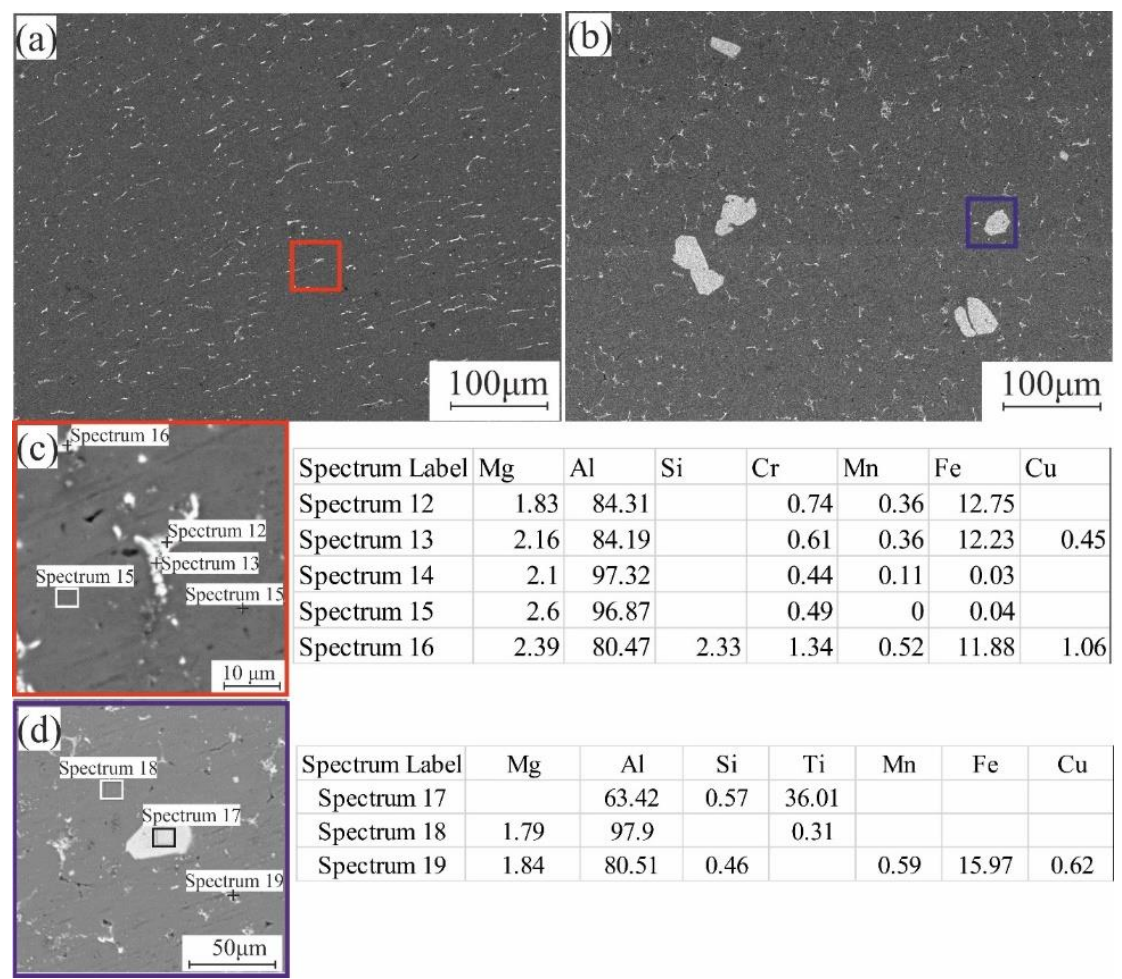

Figure 5. The as-cast SEM and EDS points analysis of investigated alloys: (a,c) Al-2.5\% Mg alloy; and (b,d) $\mathrm{Al}-2.5 \% \mathrm{Mg}+\mathrm{TiB}$.

It was confirmed by X-ray diffraction plots that there were $\mathrm{Al}_{3} \mathrm{Ti}$ and $\mathrm{TiB}_{2}$ phases present, which function as potential nucleants for the nucleation of the main phase. Regarding an explanation of the improvement in the grain refinement of aluminium alloys caused by the addition of the Al-0.5 Ti-0.1 B master alloy, several theories have described the mechanisms of the refinement and enhanced properties of the modified structures [36-38]. Grain refining in aluminium alloys requires the addition of solute atoms and the inclusion of nucleant particles. Consequently, $\mathrm{Al}_{3} \mathrm{Ti}$ production may be attributed to the grain refinement process of the Al-2.5\% Mg alloy caused by the inclusion of the Al-0.5 Ti-0.1 B master alloy. Figure 6 shows the XRD analysis of the investigated alloys. The results revealed that adding $0.5 \mathrm{wt} \% \mathrm{Ti}$ and $0.1 \mathrm{wt} \% \mathrm{~B}$ resulted in forming $\mathrm{TiB}_{2}$ and $\mathrm{Al}_{3} \mathrm{Ti}$ aside from the standard phases of $\mathrm{Al}-2.5 \% \mathrm{Mg}$, which act as inclusion centres that lead to finer grains of 
$\mathrm{Al}-2.5 \% \mathrm{Mg}+\mathrm{TiB}$. In addition, these intermetallic phases were formed around the grains on the grain boundaries, acting as a barrier to grain growth. Figure 7 shows the DSC analysis of the investigated alloys in order to determine the liquidus and solidus temperatures. The liquidus and solidus temperatures for the $\mathrm{Al}-2.5 \% \mathrm{Mg}$ alloy were $651^{\circ} \mathrm{C}$ (Figure $7 \mathrm{~b}$ ) and $609^{\circ} \mathrm{C}$ (Figure 7a), respectively; whereas the liquidus and solidus temperatures for the $\mathrm{Al}-2.5 \%, \mathrm{Mg}+\mathrm{TiB}$ alloy were $658^{\circ} \mathrm{C}$ (Figure $7 \mathrm{~b}$ ) and $602^{\circ} \mathrm{C}$ (Figure 7a), respectively. Solidus temperature was obtained by the heating curve and the liquidus temperature was obtained by the cooling curve. The alloy's solidification temperature range was approximately $42-56^{\circ} \mathrm{C}$. Adding the Ti-B increased the solidification range by $14{ }^{\circ} \mathrm{C}$. The stability was determined to be excellent because of the wide solidification range.

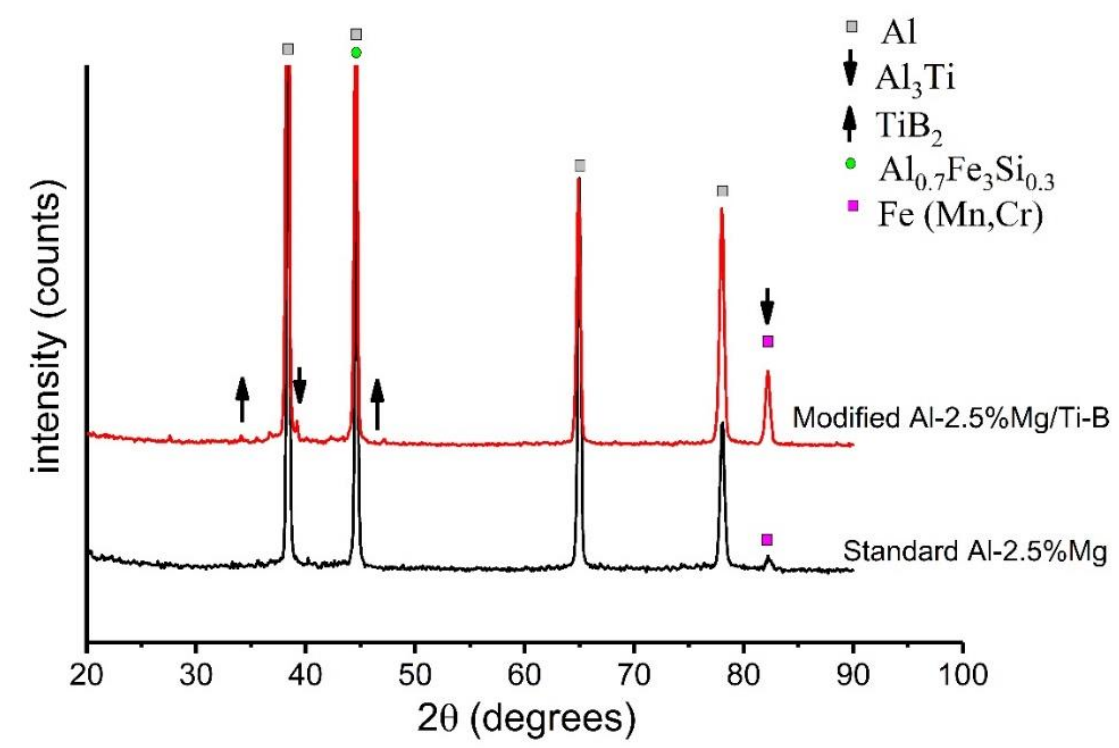

Figure 6. XRD analysis of the investigated alloys.
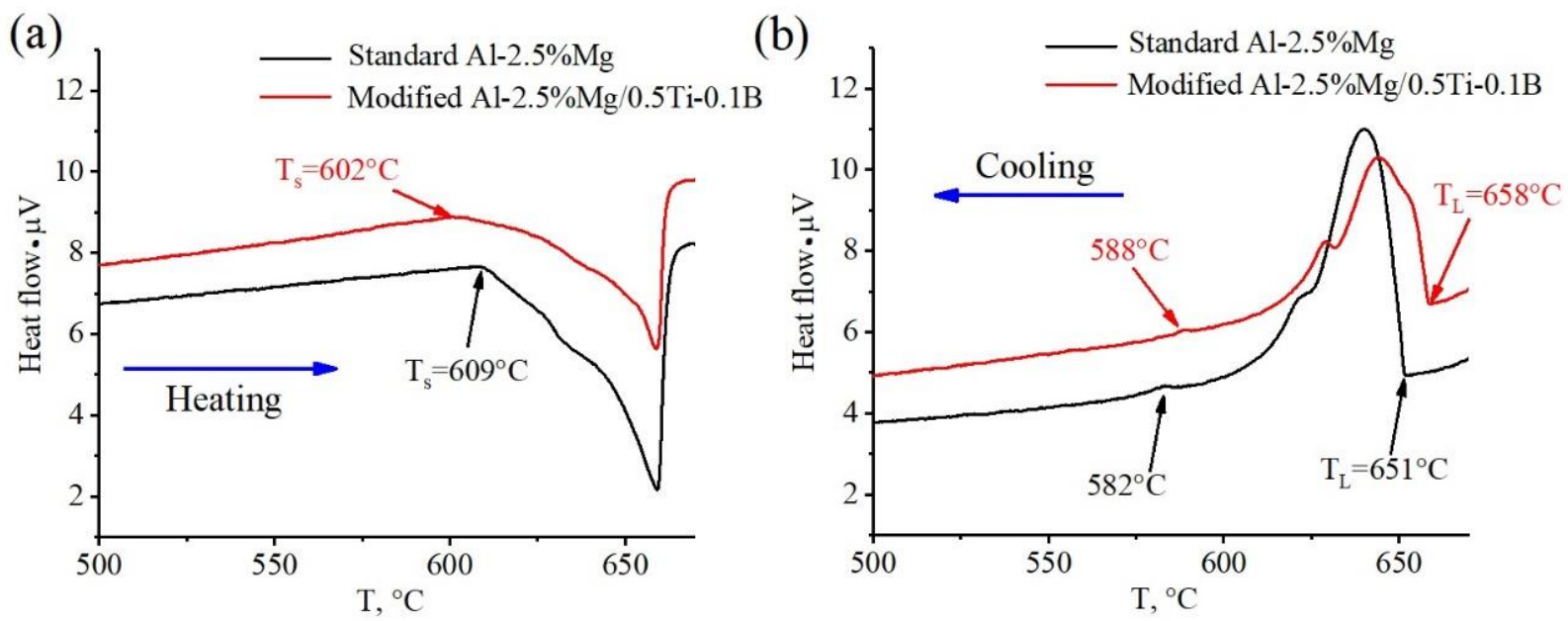

Figure 7. DSC analysis of the investigated alloys (a) heating curves and (b) cooling curves.

\subsection{Mechanical Properties Characterisation}

Figure 8 shows the engineering stress-strain curves for as-cast $\mathrm{Al}-2.5 \% \mathrm{Mg}$ and modified $\mathrm{Al}-2.5 \% \mathrm{Mg} / \mathrm{Ti}-\mathrm{B}$ alloys. The basic mechanical characteristics of any material are ductility and strength, although these attributes are often specified in opposition to one another in their specifications. Consequently, materials may be ductile or strong, but they are seldom both at the same time. The as-cast sample had a minimum ultimate 
tensile strength (UTS) and elongation. This was because the as-cast sample had a dendritic structure with coarse and continuous intermetallic compounds. As seen in Figure 8, the refined grains of the modified $\mathrm{Al}-2.5 \% \mathrm{Mg} / \mathrm{Ti}-\mathrm{B}$ alloy enhanced both the tensile strength and the elongation of the alloy. The optimal amount of grain refiners enhanced the tensile strength and elongation of the alloys' fracture. The main cause for this improvement is most likely owing to the alloy's reduced grain size, which results in a finer distribution of second phases (i.e., intermetallics). Table 2 summarises the mechanical properties of the investigated alloy. The sample's ultimate tensile strength and elongation were increased from $156 \mathrm{MPa}$ (for the as-cast sample) to $205 \mathrm{MPa}$ (modified alloy using Ti-B modifiers). The elongation of the modified Al-2.5\% Mg/Ti-B alloy samples was about $100 \%$ more than that of the as-cast sample. With the inclusion of Ti-B modifier elements, it was clear that the refined grain alloy displayed greater elongation. The yield strength of the modified alloy was insignificantly enhanced by adding Ti-B compared to the standard alloy. The increase in the yield strength was $5 \mathrm{MPa}$, while the increase in the ultimate tensile strength was $40 \mathrm{MPa}$. In the same manner, the Young's modulus was increased by $4 \mathrm{GPa}$. Generally, the overall enhancement in the mechanical properties was satisfactory, which underlies this alloy's wide use in many industrial applications.

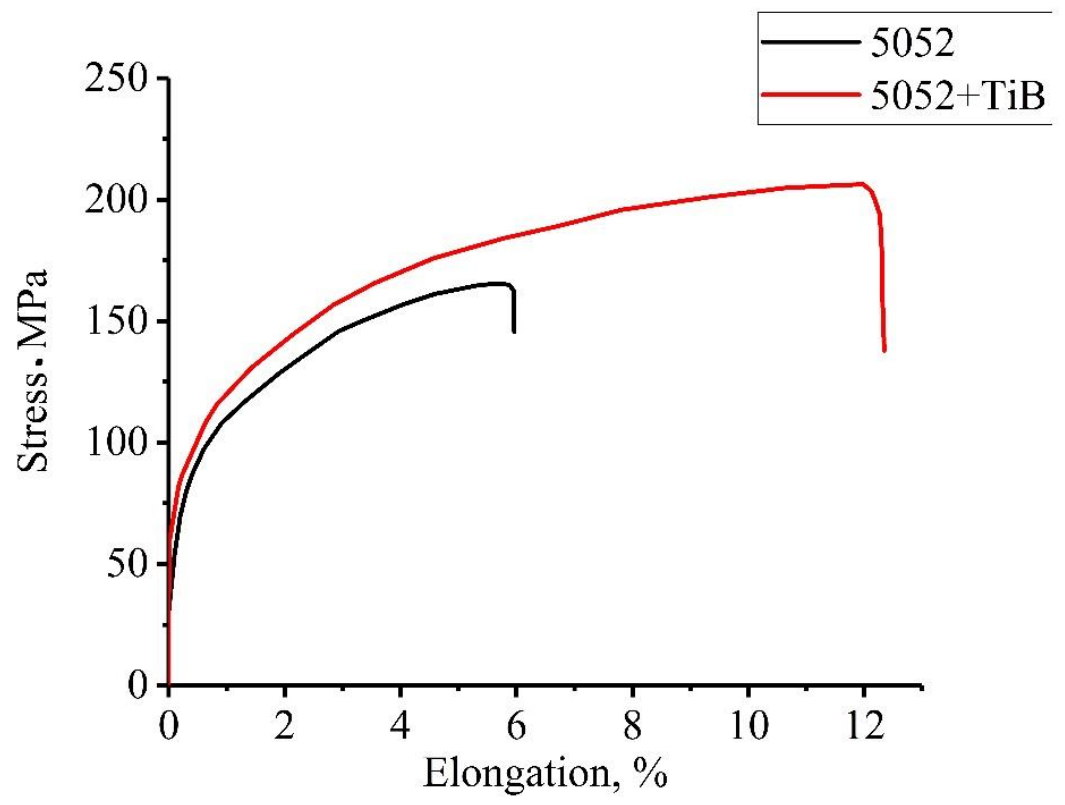

Figure 8. Stress-elongation dependence of the investigated alloys.

Table 2. Mechanical properties of the investigated alloys from tensile test.

\begin{tabular}{ccccc}
\hline Alloy & Yield Strength MPa & $\begin{array}{c}\text { Ultimate Tensile } \\
\text { Strength, MPa }\end{array}$ & $\begin{array}{c}\text { Youngs Modulus } \\
\text { GPa }\end{array}$ & Elongation, \% \\
\hline $\mathrm{Al}-2.5 \% \mathrm{Mg}$ & $80 \pm 4$ & $165 \pm 6$ & $60.5 \pm 3$ & $5.9 \pm 3$ \\
\hline $\mathrm{Al}-2.5 \% \mathrm{Mg} / \mathrm{Ti}-\mathrm{B}$ & $86 \pm 4$ & $206 \pm 5$ & $64 \pm 3$ & $12.2 \pm 3$ \\
\hline
\end{tabular}

\subsection{Hardness Evaluation}

Hardness is considered to be a good indicator for the other mechanical properties. Figure 9 shows the Vickers hardness results of the investigated alloys. Interestingly, the improved $\mathrm{Al}-2.5 \% \mathrm{Mg} / \mathrm{TiB}$ alloy had a Vickers hardness of about $67 \mathrm{HV}$, which is roughly $18 \%$ higher than the as-cast alloy ( $55 \mathrm{HV}$ ). The intermetallic compounds (ICs) are thought to have a significant effect on the properties of the modified alloy [39]. This is primarily due to Ti and B reacting at higher temperatures during the casting process to produce intermetallic 
compounds. These intermetallic compounds $\left(\mathrm{Al}_{3} \mathrm{Ti}_{1}, \mathrm{TiB}_{2}\right.$, etc.) have significantly higher hardness, resulting in a considerable increase in hardness at the $\mathrm{Al}-\mathrm{Mg}$ interface. The results revealed that the hardness was increased by adding $0.5 \mathrm{Ti}+0.1 \mathrm{~B}$ due to the formed intermetallic phases and the refined structure. As a result, plastic deformation becomes more difficult, eventually increasing hardness at the bonding interface. Furthermore, the distribution and quantity of intermetallic compounds in Al-Mg alloy materials may be relevant.

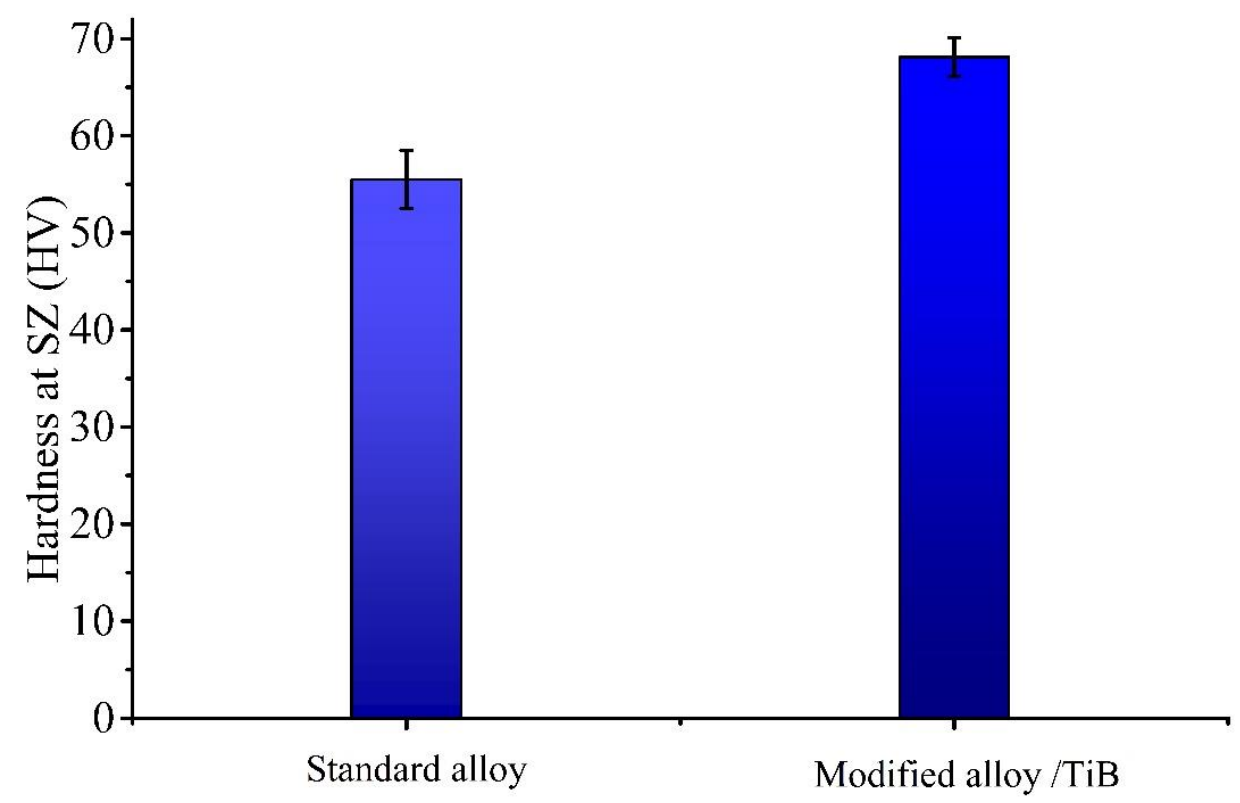

Figure 9. The hardness of the investigated alloys.

\subsection{Corrosion}

Intergranular corrosion (IGC) occurs when the electrochemical potential difference between an alloy's intermetallic components corrodes the intergranular component. The samples were cut into parts with dimensions of $25 \times 15 \times 2 \mathrm{~mm}^{3}$, and subsequently ground to 2400 level grit and finally polished and captured. The main aim of the IGC test is to show the effect of grain refining on the corrosion behaviour, so the samples were visually examined. This type of corrosion is developed on the grain boundaries and does not cause significant damage to the grains themselves. IGC can take on various forms depending on the alloying elements and heat treatment used. Intergranular corrosion infiltrates more rapidly than pitting corrosion, although it eventually reaches a depth that is self-limiting in its penetration. Even though aluminium-magnesium alloy containing less than $3 \% \mathrm{Mg}$ has excellent corrosion resistance, the high proportion of $\mathrm{Mg}$ causes intergranular corrosion during the joining process or as a result of surface modification methods. According to the results, the IGC rate in the as-cast sample rose due to the dendritic structure of the grains and their large size. Hence, the precipitates at the grain boundaries significantly impacted the corrosion rate $[13,40]$. Figure 10 represents a micrograph of the studied alloys taken immediately after $24 \mathrm{~h}$ of immersion in the solution without any surface preparation. The results revealed that the intergranular corrosion began as tiny pits and spread quickly throughout the intergranular pathways (Figure 10a,b). In contrast, the modified $\mathrm{Al}-2.5 \% \mathrm{Mg} / \mathrm{Ti}-\mathrm{B}$ alloy exhibited improved corrosion resistance owing to the Ti-B addition (Figure 10c,d). 

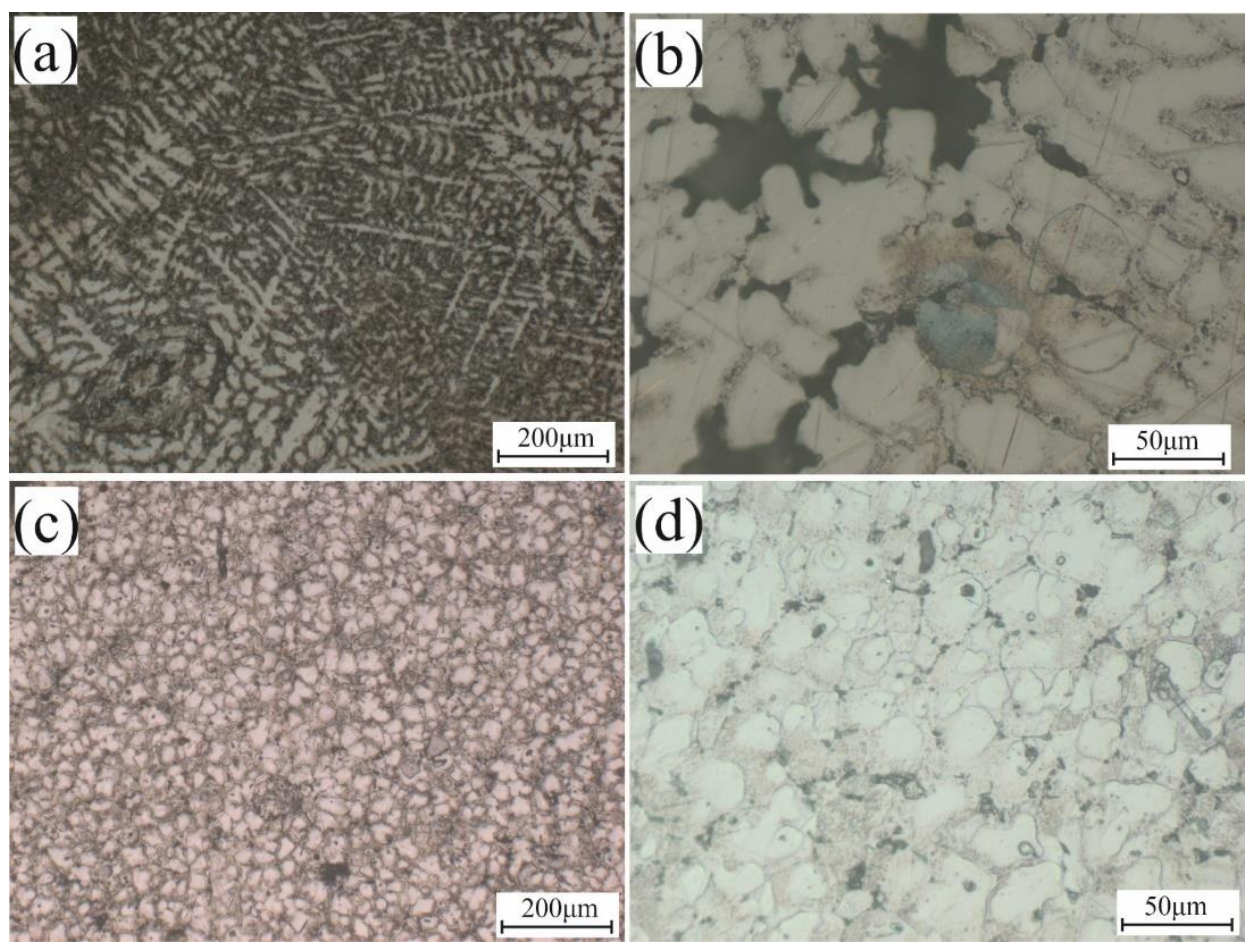

Figure 10. Microstructure after intergranular corrosion of the investigated alloys: (a) as-cast Al-2.5\% $\mathrm{Mg}$; (b) as cast $\mathrm{Al}-2.5 \% \mathrm{Mg}$ after $24 \mathrm{~h}$ corrosion; (c) modified Al-2.5\% Mg/Ti-B; and (d) the modified $\mathrm{Al}-2.5 \% \mathrm{Mg} / \mathrm{Ti}-\mathrm{B}$ after corrosion.

\subsection{Finite Element Model Results}

Figure 11 shows the simulated resonant of the first three modes; however, the resonant frequencies were high due to the dimension of the sample and the closeness of the values between both investigated cases. The simulated frequency response function (FRF) is considered the main parameter worth studying due to its importance in structural applications. Hence, the harmonic response behaviour is built on the modal analysis in the simulation module. The simulated standard alloy showed less resonant frequency at the first three mode shapes than the modified alloy by $43 \mathrm{~Hz}, 69 \mathrm{~Hz}$, and $278.2 \mathrm{~Hz}$, respectively, as demonstrated in Table 3 . The predicted natural frequency of the modified alloy increased by a fixed rate of $3.17 \%$ more than the standard alloy. The simulated results revealed that the resonance frequencies at higher modes increased for the modified alloy; hence, this improvement leads to stability when exposed to a high excitation source. This result matched the experimental free vibration test, as shown in Figure 12. The experimental natural frequency at the first mode of the standard alloy showed a value larger than the numerical value by only $14 \mathrm{~Hz}$. While the modified alloy showed a variation of $28 \mathrm{~Hz}$ for the numerical model, these values reveal the closeness between the measured frequency and the theoretical values. Therefore, improvement in the mechanical properties leads to enhancing the dynamic properties via increasing the natural frequency. Moreover, the high damping capacity of the metal leads to a rise in the safety rate in marine and vehicle industries. 

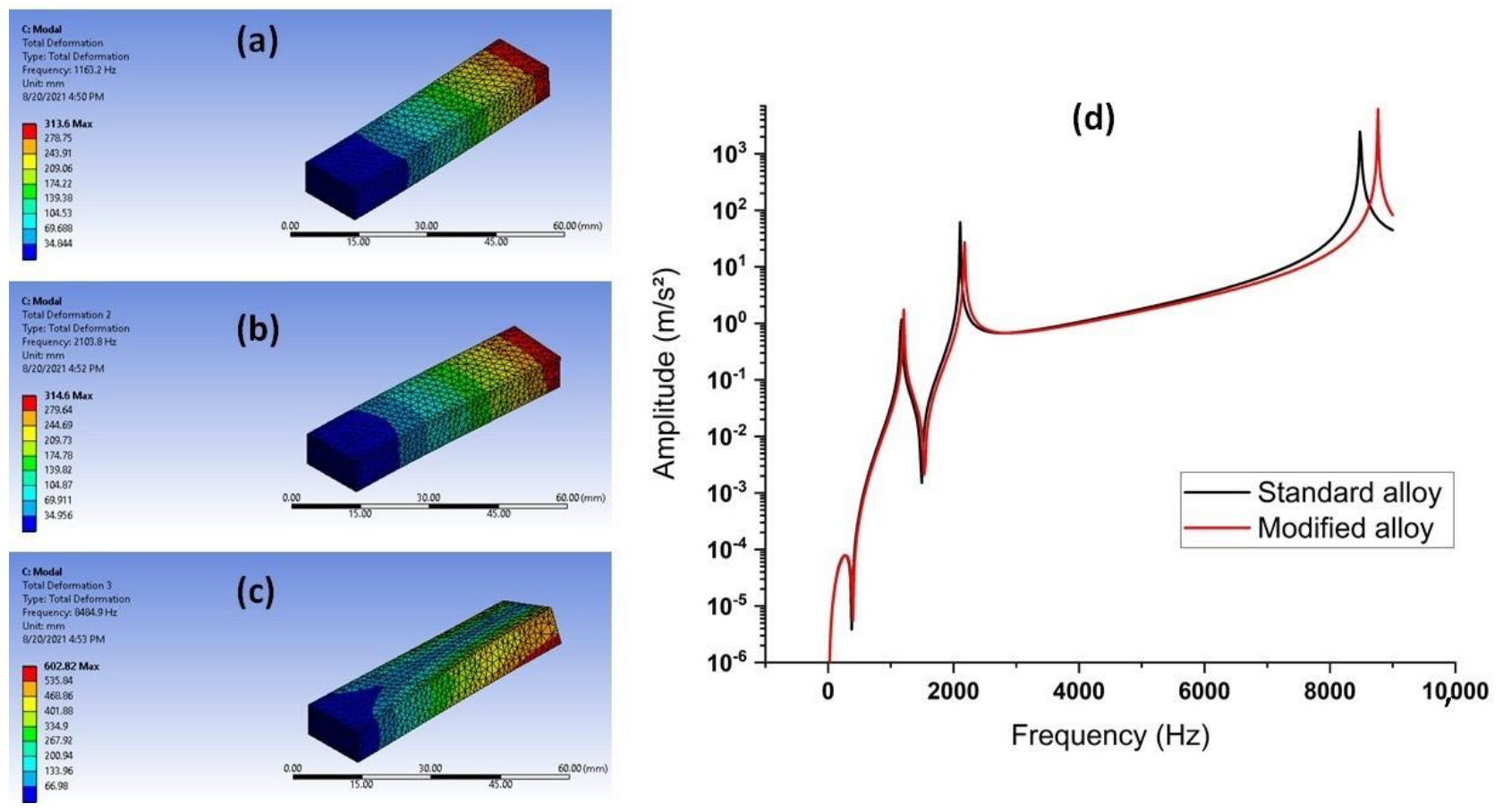

Figure 11. (a) First mode shape; (b) second mode shape; (c) third mode shape simulation analysis of the standard Al-2.5\% $\mathrm{Mg}$ alloy; and (d) simulation of modal analysis for the studied alloys using FRF representation.

Table 3. The eigenvalue of the resonant frequencies at the first six modes.

\begin{tabular}{ccc}
\hline $\begin{array}{c}\text { Resonance } \\
\text { Mode Number }\end{array}$ & $\begin{array}{c}\text { The Resonance Frequency of } \\
\text { Standard Al-2.5\% Mg Alloy (Hz) }\end{array}$ & $\begin{array}{c}\text { The Resonance Frequency of Modified } \\
\text { Al-2.5\% Mg/Ti-B Alloy (Hz) }\end{array}$ \\
\hline 1 & 1167.0 & 1210.0 \\
\hline 2 & 2103.8 & 2172.8 \\
\hline 3 & 8484.9 & 8763.1 \\
\hline 4 & 9625.1 & 9940.7 \\
\hline 5 & $15,163.0$ & $15,660.0$ \\
\hline 6 & $17,221.0$ & $17,786.0$ \\
\hline
\end{tabular}

\subsection{Dynamic Characteristics}

The as-cast Al-2.5\% Mg alloy showed a natural frequency lower than the modified alloy containing Ti-B modifiers. The experimental free vibration test showed the time decay curves of both conditions; Figure 13a shows a long-time response for the as-cast Al-2.5\% $\mathrm{Mg}$ alloy, while the modified alloy showed less time decay. Changes in the microstructure and size of refined grains can explain the difference in the time response in each case. As the mechanical properties were enhanced, the dynamic properties also improved due to increasing the first-mode resonant frequency. Figure 12 shows an increase in the natural frequency of the modified Al-2.5\% Mg alloy by $7 \%$. The damping ratio $(\zeta)$ of the standard Al-2.5\% Mg alloy was $3.28 \pm 0.0029 \%$, whereas the modified Al-2.5\% Mg alloy Ti-B was $5.61 \pm 0036 \%$. The values were consistent with the damping cross-references [41]. The refined grains played an essential role in the dynamic properties - that is, the existence of the extra grain boundaries impeded the exciting vibration waves when transmitted from one grain to another [33]. Table 4 shows the dynamic characterisation of the investigated alloys. The quality factor $(Q)$ provides a more reliable indication of the dynamic properties of the structure. When an external force is applied to a resonator, the $Q$ factor is described 
as the resonator's centre frequency ratio to its bandwidth. A higher $\mathrm{Q}$ indicates a slower rate of energy loss and slower decay of oscillations.

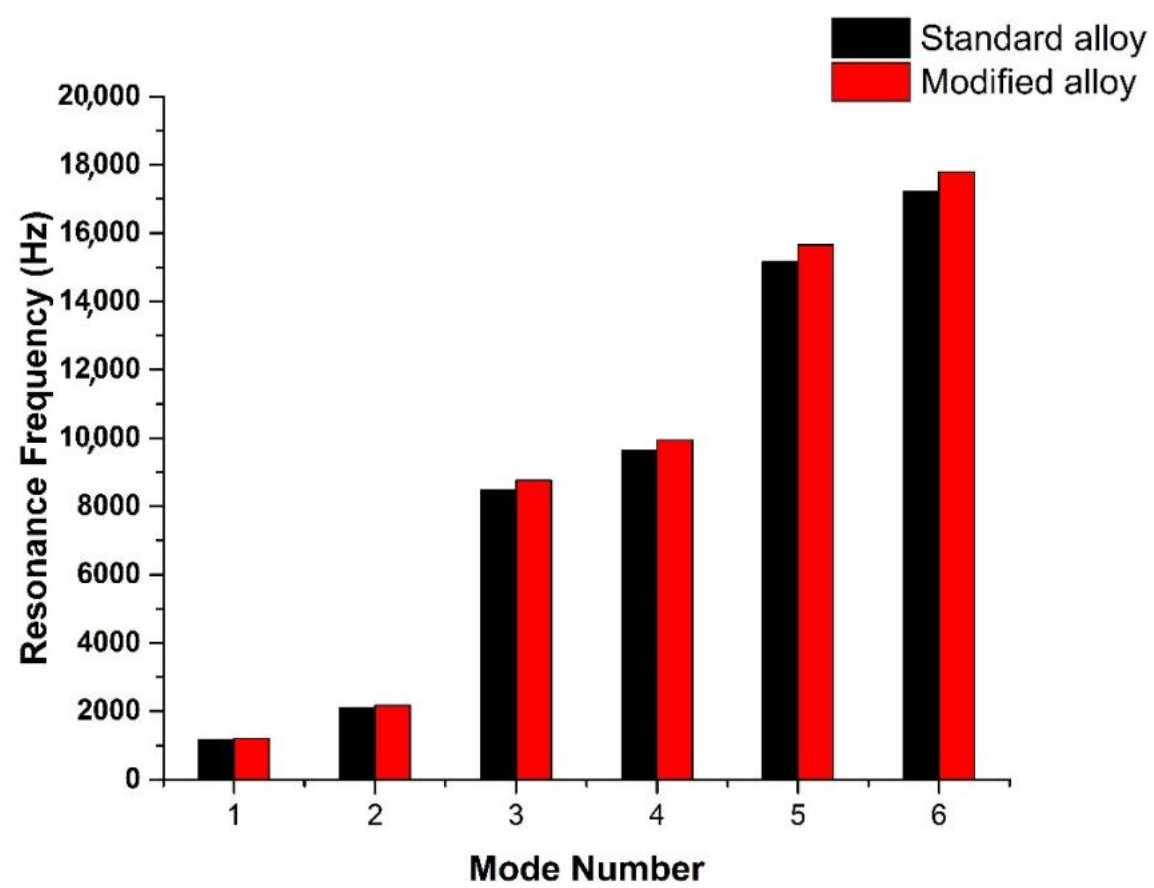

Figure 12. Graphical representation of the simulation results of the resonant frequencies at the first six modes.
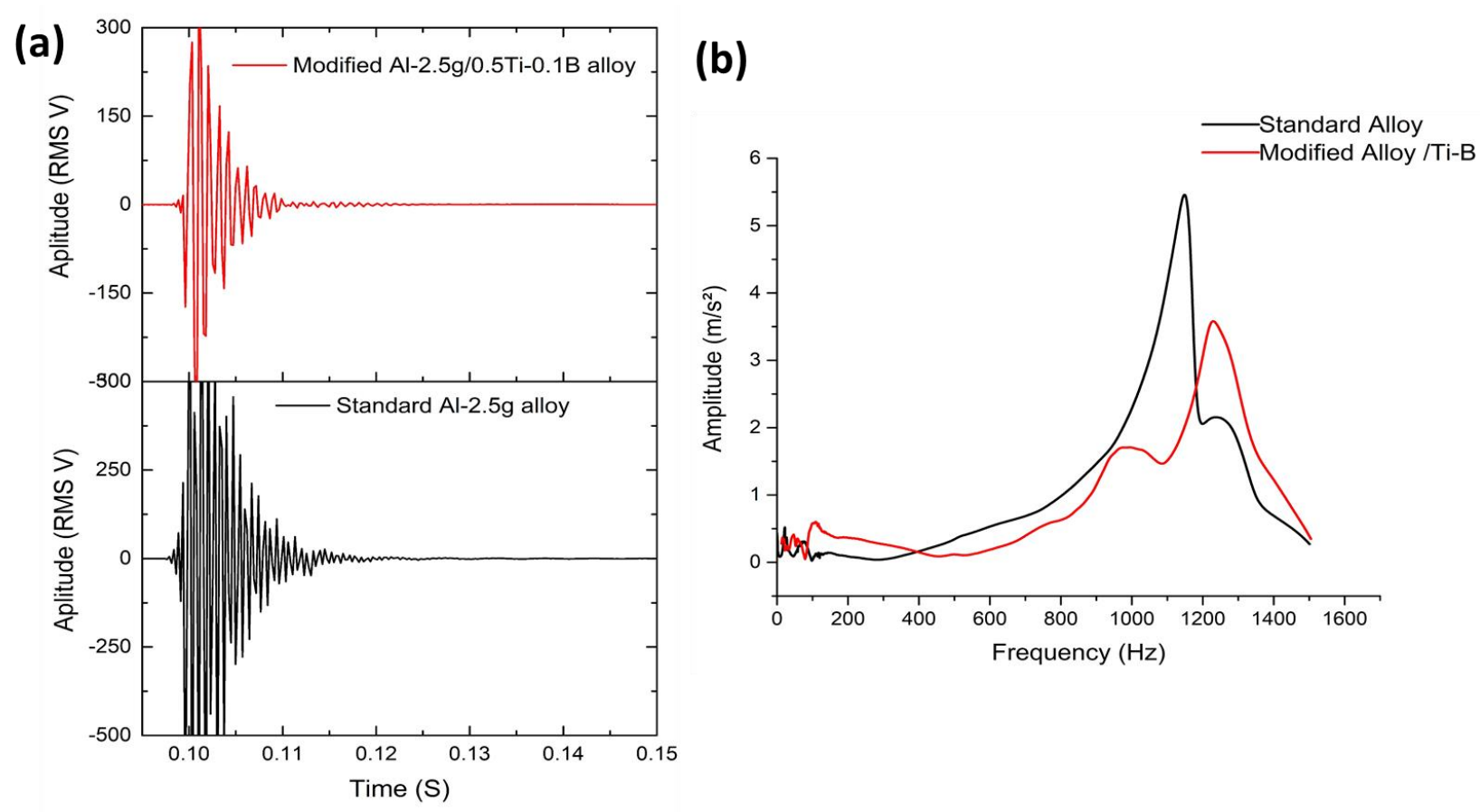

Figure 13. (a) Experimental time decay response; (b) frequency response function (FRF). 
Table 4. Experimental dynamic properties.

\begin{tabular}{cccc}
\hline Alloy & $\begin{array}{c}\text { Resonant Frequency } \\
(\mathbf{H z})\end{array}$ & $\begin{array}{c}\text { Damping Ratio } \\
\mathbf{\%}(\zeta)\end{array}$ & $\begin{array}{c}\text { Quality Factor } \\
(\mathbf{Q})\end{array}$ \\
\hline $\mathrm{Al}-\% 2.5 \mathrm{Mg}$ Standard alloy & 1149 & 0.0321 & 15.57 \\
\hline $\mathrm{Al}-2.5 \% \mathrm{Mg} / \mathrm{Ti}-\mathrm{B}$ Modified & 1228 & 0.0573 & 8.72 \\
\hline
\end{tabular}

Resonant frequency employing the mathematical equation was used to validate the natural frequency value obtained from the experimental results. Table 5 shows the comparison between the two methods; hence, the mathematical formula in Equation (5) was used to calculate the theoretical value of the first resonance mode only. The experimental resonance frequencies were closed to the theoretical values; thus, it was considered an indicator of the validity of the laboratory results. On the other hand, knowing the theoretical resonance value that depends on the mechanical properties can help predict the damping capacity by adapting their parameters using FEM analysis in future work.

Table 5. Comparison of the theoretical value of the first mode resonance frequency and the experimentally measured value.

\begin{tabular}{ccc}
\hline \multirow{2}{*}{ Alloy } & \multicolumn{2}{c}{ Resonant Frequency } \\
\cline { 2 - 3 } & Theorical Value (Hz) & Experimental Value (Hz) \\
\hline Al- $\% 2.5 \mathrm{Mg}$ Standard alloy & 1167 & 1149 \\
\hline Al-2.5\% Mg/Ti-B Modified & 1210 & 1228 \\
\hline
\end{tabular}

\section{Conclusions}

In this study, standard $\mathrm{Al}-2.5 \% \mathrm{Mg}$ cast alloy was modified using Ti-B modifier elements; the following results were concluded from this investigation.

The presence of titanium and boron in Al-Mg alloys produced excellent grain refinement that causes an improvement in the mechanical properties: thus, the enhancement in tensile strength by $30.5 \%$ and elongation by $100 \%$. On the other hand, there was a slight enhancement in the hardness behaviour of the modified $\mathrm{Al}-2.5 \% \mathrm{Mg} / \mathrm{TiB}$ alloy due to the formation of intermetallic phases.

The standard Al-2.5\% Mg cast alloy showed intergranular corrosion that started in tiny pits and soon expanded across the dendritic grain boundaries. The modified $\mathrm{Al}-2.5 \%$ $\mathrm{Mg} / \mathrm{Ti}-\mathrm{B}$ alloy exhibited improved corrosion resistance owing to the refined and minimised grain structure.

The modified alloy's dynamic properties were improved because increasing the number of grain boundaries helps absorb the amplitude of the propagated waves passing through these grains. However, there is no significant change in the resonance frequency, which is increased by $6.9 \%$ than the standard alloy.

The recommendation for further work is to study the distribution of the refined grains caused by the modifier's elements on the fabricated cast and their influence on the manufacturing process.

Author Contributions: H.M.A. and H.A.M.A.; methodology, E.B.M. and M.H.; software, E.B.M.; validation, H.A.M.A.; formal analysis, M.H.; investigation, E.B.M.; resources, H.A.M.A.; data curation, H.M.A.; writing—original draft preparation, E.B.M.; writing-review and editing, M.H.; visualization, H.A.M.A.; supervision, M.H.; project administration, H.M.A.; funding acquisition, H.M.A. All authors have read and agreed to the published version of the manuscript.

Funding: This project was funded by the Deanship of Scientific Research (DSR), King Abdul-Aziz University, under Grant No. (D-134-135-1441).

Data Availability Statement: Not applicable. 
Acknowledgments: This project was funded by the Deanship of Scientific Research (DSR), King Abdulaziz University, Jeddah, under Grant No. (D-134-135-1441). The authors, therefore, gratefully acknowledge DSR technical and financial support.

Conflicts of Interest: The authors declare no conflict of interest.

\section{References}

1. Jahedi, M.; Mani, B.; Shakoorian, S.; Pourkhorshid, E.; Paydar, M.H. Deformation rate effect on the microstructure and mechanical properties of Al-SiCp composites consolidated by hot extrusion. Mater. Sci. Eng. A 2012, 556, 23-30. [CrossRef]

2. Shanmugasundaram, T.; Heilmaier, M.; Murty, B.S.; Sarma, V.S. Microstructure and Mechanical Properties of Nanostructured Al-4Cu Alloy Produced by Mechanical Alloying and Vacuum Hot Pressing. Metall. Mater. Trans. A 2009, 40, 2798-2801. [CrossRef]

3. Zhou, S.M.; Zhang, X.B.; Ding, Z.P.; Min, C.Y.; Xu, G.L.; Zhu, W.M. Fabrication and tribological properties of carbon nanotubes reinforced $\mathrm{Al}$ composites prepared by pressureless infiltration technique. Compos. Part A Appl. Sci. Manuf. 2007, 38, 301-306. [CrossRef]

4. AbuShanab, W.S.; Essam, B.; Moustafa, E.; Ghandourah, E.; Taha, M.A. The Effect of Different Fly Ash and Vanadium Carbide Contents on the Various Properties of Hypereutectic Al-Si Alloys-Based Hybrid Nanocomposites. Res. Sq. 2021. [CrossRef]

5. Moustafa, E.B.; AbuShanab, W.S.; Ghandourah, E.; Taha, M.A. Microstructural, mechanical and thermal properties evaluation of AA6061 $/ \mathrm{Al}_{2} \mathrm{O}_{3}-\mathrm{BN}$ hybrid and mono nanocomposite surface. J. Mater. Res. Technol. 2020, 9, 15486-15495. [CrossRef]

6. Chen, Z.; Kang, H.; Fan, G.; Li, J.; Lu, Y.; Jie, J.; Zhang, Y.; Li, T.; Jian, X.; Wang, T. Grain refinement of hypoeutectic Al-Si alloys with B. Acta Mater. 2016, 120, 168-178. [CrossRef]

7. Zhao, J.; Shi, M.; Wang, Z.; Xu, L. Effect of a New Grain Refiner (Al-Ti-Mg-Ce) on Hardness, Tensile, and Impact Properties of Al-7Si Alloy. Metals 2019, 9, 228. [CrossRef]

8. AbuShanab, W.S.; Moustafa, E.B. Effects of friction stir processing parameters on the wear resistance and mechanical properties of fabricated metal matrix nanocomposites (MMNCs) surface. J. Mater. Res. Technol. 2020, 9, 7460-7471. [CrossRef]

9. Moustaf, E.B.; Khalil, A.M.; Ahmed, H.M.; Hefni, M.; Mosleh, A.O. Microstructure, Hardness, and Wear Behavior Investigation of the Surface Nanocomposite Metal Matrix Reinforced by Silicon Carbide and Alumina Nanoparticles. J. Miner. Met. Mater. Eng. 2021, 7, 57-62.

10. Hwang, J.Y.; Doty, H.W.; Kaufman, M.J. The effects of Mn additions on the microstructure and mechanical properties of Al-Si-Cu casting alloys. Mater. Sci. Eng. A 2008, 488, 496-504. [CrossRef]

11. Easton, M.A.; StJohn, D.H. A model of grain refinement incorporating alloy constitution and potency of heterogeneous nucleant particles. Acta Mater. 2001, 49, 1867-1878. [CrossRef]

12. Górny, M.; Sikora, G.; Kawalec, M. Effect of Titanium and Boron on the Stability of Grain Refinement of Al-Cu Alloy. Arch. Foundry Eng. 2016, 16, 35-38. [CrossRef]

13. Moustafa, E.B.; Mosleh, A.O. Effect of (Ti-B) modifier elements and FSP on 5052 aluminum alloy. J. Alloys Compd. 2020, 823, 153745. [CrossRef]

14. Wang, X.J.; Cong, X.; Muhammad, A.; Hanada, S.; Yamagata, H.; Wang, W.H. Effects of Al-Ti-B-RE grain refiner on microstructure and mechanical properties of Al-7.0Si-0.55Mg alloy. Trans. Nonferrous Met. Soc. China 2014, 24, 2244-2250. [CrossRef]

15. Easton, M.A.; Qian, M.; Prasad, A.; StJohn, D.H. Recent advances in grain refinement of light metals and alloys. Curr. Opin. Solid State Mater. Sci. 2016, 20, 13-24. [CrossRef]

16. Fayomi, O.S.I.; Popoola, A.P.I.; Udoye, N.E. Effect of Alloying Element on the Integrity and Functionality of Aluminium-Based Alloy, in Aluminium Alloys-Recent Trends in Processing, Characterization, Mechanical Behavior and Applications; IntechOpen: London, UK, 2017.

17. Sharma, A.; Shin, Y.S.; Jung, J.-P. Influence of Various Additional Elements in Al Based Filler Alloys for Automotive and Brazing Industry. J. Weld. Join. 2015, 33, 1-8. [CrossRef]

18. Sigworth, G.K.; Kuhn, T.A. Grain Refinement of Aluminum Casting Alloys. Int. J. Met. 2007, 1, 31-40. [CrossRef]

19. Bouchet, J.; Jacquelin, E.; Hamelin, P. Static and dynamic behavior of combined composite aluminium tube for automotive applications. Compos. Sci. Technol. 2000, 60, 1891-1900. [CrossRef]

20. Moćko, W.; Kowalewski, Z. Dynamic Properties of Aluminium Alloys Used in Automotive Industry. J. KONES. Powertrain Transp. 2015, 19, 345-351. [CrossRef]

21. Mantry, S.; Behera, D.; Mishra, S.K.; Debasish, D.; Jha, B.B.; Mishra, B.K. Erosive Wear Analysis of Plasma-Sprayed Cu Slag-Al Composite Coatings. Tribol. Trans. 2013, 56, 196-202. [CrossRef]

22. Rajahram, S.S.; Harvey, T.J.; Wood, R.J.K. Evaluation of a semi-empirical model in predicting erosion-corrosion. Wear 2009, 267, 1883-1893. [CrossRef]

23. Chalfoun, D.R.; Kappes, M.A.; Chocrón, M.; Rebak, R.B. Localized Corrosion of UNS A95052 Aluminum Alloy for Application in Multi-Effect Desalinator Plants. Corrosion 2018, 74, 1023-1032. [CrossRef]

24. Moustafa, E.B.; Almitani, K.H. Detecting Damage in Carbon Fibre Composites using Numerical Analysis and Vibration Measurements. Latin Am. J. Solids Struct. 2021, 18. [CrossRef]

25. Chouinard, L.; Shahsavari, V.; Bastien, J. Reliability of Wavelet Analysis of Mode Shapes for the Early Detection of Damage in Beams. Front. Built Environ. 2019, 5, 91. [CrossRef] 
26. Zhang, Z.; Zeng, X.; Ding, W. The influence of heat treatment on damping response of AZ91D magnesium alloy. Mater. Sci. Eng. A 2005, 392, 150-155. [CrossRef]

27. Al-Badrawy, A.E. Grain size effects on the internal friction and mechanical properties of zn-22\% al alloy. In Proceedings of the Fourth Assiut University International Conference on Mechannical Engineering and advanced Technology for Industrial Production, Assiut, Egypt, 12-14 December 2006; pp. 215-223.

28. Alexopoulos, N.D.; Pantelakis, S.G. Quality evaluation of A357 cast aluminum alloy specimens subjected to different artificial aging treatment. Mater. Des. 2004, 25, 419-430. [CrossRef]

29. Samuel, E.; Golbahar, B.; Samuel, A.M.; Doty, H.W.; Valtierra, S.; Samuel, F.H. Effect of grain refiner on the tensile and impact properties of Al-Si-Mg cast alloys. Mater. Des. 2014, 56, 468-479. [CrossRef]

30. Moustafa, E.; Mohammed, S.; Abdel-Wanis, S.; Mahmoud, T.; El-Kady, E.S. Characterization of elastic modulus for AA2024/ $\mathrm{Al}_{2} \mathrm{O}_{3}$ Nanocomposite beam obtained from dynamic and static methods. Int. J. Res. Dev. Technol. 2016, 6, 124-128.

31. AbuShanab, W.S.; Moustafa, E.B.; Hammad, A.H. Dependence of the structure, optical, and dynamic properties of novel cadmium phosphate glass on vanadium content. J. Mater. Res. Technol. 2020, 9, 14178-14189. [CrossRef]

32. AbuShanab, W.S.; Moustafa, E.B. Detection of Friction Stir Welding Defects of AA1060 Aluminum Alloy Using Specific Damping Capacity. Materials 2018, 11, 2437. [CrossRef]

33. Moustafa, E.B. Dynamic Characteristics Study for Surface Composite of AMMNCs Matrix Fabricated by Friction Stir Process. Materials 2018, 11, 1240. [CrossRef] [PubMed]

34. Gowid, S.; Mahdi, E.; Youssef, S.S.; Moustafa, E.; Mosleh, A.; Shokry, A. Experimental investigation of the dynamic characteristics of wrapped and wound fiber and metal/fiber reinforced composite pipes. Compos. Struct. 2021, 276, 114569. [CrossRef]

35. Farahani, M.V.; Emadoddin, E.; Emamy, M.; Raouf, A.H. Effect of grain refinement on mechanical properties and sliding wear resistance of extruded Sc-free 7042 aluminum alloy. Mater. Des. 2014, 54, 361-367. [CrossRef]

36. Johnsson, M. On the mechanism of grain refinement of aluminium after additions of Ti and B. In Proceedings of the Light Metals: Proceedings of the Sessions, TMS Annual Meeting, Warrendale, PA, USA, 21-25 February 1993.

37. Cibula, A. Discussion of "the mechanisms of grain refinement in dilute aluminum alloys"*. Metall. Trans. 1972, 3, 751-753. [CrossRef]

38. Kumar, D.D.; Crippen, K.J. Science Education in Review: Response to the Secretary's Summit of 2004. J. Sci. Educ. Technol. 2005, 14, 143-145. [CrossRef]

39. Kim, K.; Kim, D.; Park, K.; Cho, M.; Cho, S.; Kwon, H. Effect of Intermetallic Compounds on the Thermal and Mechanical Properties of Al-Cu Composite Materials Fabricated by Spark Plasma Sintering. Materials 2019, 12, 1546. [CrossRef] [PubMed]

40. Łakoma, P.; Ditze, A.; Scharf, C. Dendritic structure formation of magnesium alloys for the manipulation of corrosion properties: Part 1-Microstructure. Int. J. Mater. Res. 2018, 109, 1081-1091. [CrossRef]

41. Adams, V.; Askenazi, A. Building Better Products with Finite Element Analysis, 1st ed.; OnWord Press: Santa Fe, NM, USA, 1999. 